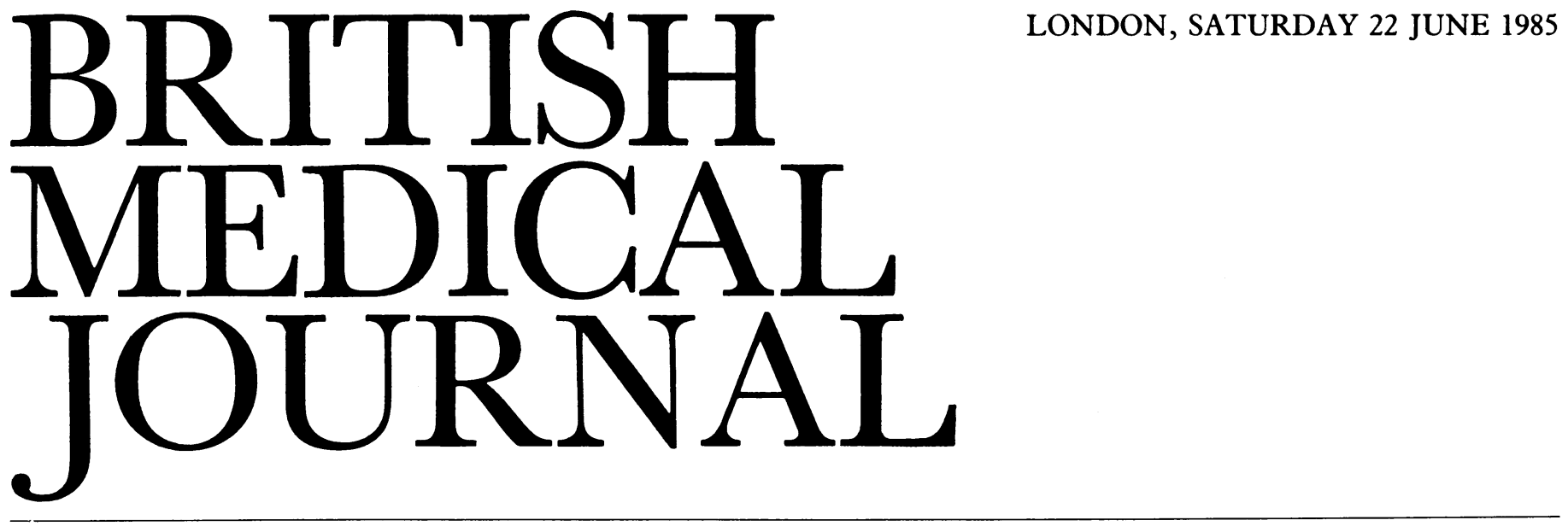

\title{
Rational drug treatment of dementia?
}

Among the drugs advocated for the treatment of dementia the most widely used are "cerebral metabolic enhancers" and centrally acting vasodilators (some of which are said also to enhance cerebral metabolism). To these may now be added drugs which act at various sites in the cholinergic system and a miscellaneous group which includes opioid antagonists, adrenergic agonists, "nootropics," anticonvulsants, and related compounds. In the light of what is known of the pathophysiology of various types of dementia how good are the reasons for using such drugs?

The most common causes of dementia are the Alzheimer process and multiple infarcts, and the two may coexist. It now seems likely that there are at least two types of Alzheimer's disease, which share certain features but which differ in important pathological and biochemical features. ${ }^{12}$ Type 1 Alzheimer's disease usually, but not invariably, begins in the late 70s. Cell loss in the brain is not increased when compared with age matched controls, but the other stigmata of Alzheimer's disease are seen-numerous senile plaques and neurofibrillary tangles, the latter being found in the neocortex, a distribution which is not seen in the normal aged brain. Type 2 Alzheimer's disease usually begins earlier than type 1 , and substantial cell loss is evident in many areas including the main noradrenergic and cholinergic subcortical nuclei. As in type 1 , senile plaques and neurofibrillary tangles are widespread, but in type 2 they are much more numerous.

Both types of Alzheimer's disease share a biochemical deficit in the presynaptic component of the cholinergic system, but in type 1 this deficiency of choline acetyltransferase is found only in the temporal lobe. In type 2 abnormalities may be present in other neurotransmitter systems, somatostatin being consistently reported as abnormal in terms of its immunoreactivity in the cerebral cortex ${ }^{3}$ but there are conflicting views about the noradrenergic, ${ }^{45}$ serotoninergic, ${ }^{67}$ and dopaminergic systems. $^{8}$

While the concept of types 1 and 2 Alzheimer's disease has many supporters, Ball et al and Hyman et al have argued that the fundamental pathological lesions lie in the hippocampus and that these lesions alone form a sufficient cause for the clinical picture seen in patients with Alzheimer's disease. ${ }^{9}{ }^{10}$

Multiple infarct dementia is also proving to be a somewhat heterogeneous condition. Typically the dementia is caused by infarction of the cerebral cortex with multiple or large single lesions. Increasing refinement of neuroradiology has made clinical diagnosis possible in Binswanger's disease, in

(C) BRITISH MEDICAL JOURNAL 1985. All reproduction rights reserved. which the infarcted areas are confined to the white matter of the brain and which is associated with systemic hypertension. In neither type is there necessarily any correlation between peripheral vascular disease and cerebral vascular lesions.

Investigation of cerebral metabolism in dementia has also been helped by new advances in technology. Positron emission tomography has been used to assess cerebral metabolism in healthy aged people in whom no convincing or consistent abnormalities have been found. ${ }^{11}$ In Alzheimer's disease abnormalities in glucose metabolism have been reported which are said to correlate with the severity of the dementia. In one study the most severely demented patients had disease of early onset, and these showed the greatest deficits. ${ }^{12}$ Chase et al have confirmed this finding for type 2 cases. ${ }^{13}$ These and earlier studies of cerebral metabolism in Alzheimer's disease may possibly be reflecting yet another difference between type 1 and type 2 cases in that only in type 2 is cerebral metabolism severely deranged-but positron emission tomography may not yet be sensitive enough to detect small though functionally important changes in cerebral metabolism.

Both cerebral blood flow and oxygen utilisation (in grey matter) decline with aging, but, as Fieschi and Lenzi have cogently argued, the homoeostatic milieu in the aging brain is maintained by a compensatory increase in the oxygen extraction ratio. ${ }^{14}$ They comment "A decreased supply does not 'per se' represent a sufficient reason for the creation of a pathological condition. That is, a reduced regional cerebral blood flow does not always represent a pathological condition." Positron emission tomography data in multiple infarct dementia show a global and regional decrease in cerebral blood flow and oxygen utilisation but also indicate that the oxygen extraction ratio may be normal or reduced depending on how well the compensatory mechanism is functioning. ${ }^{14}$

Such pathophysiological findings call into question the current use of cerebral metabolic enhancers and centrally acting vasodilators. Some centrally acting vasodilators (for example, isoxsuprine) are still being recommended for the treatment of cerebrovascular disorders, but there is neither a scientific rationale nor clinical evidence for such a practice. ${ }^{15}$ Other centrally acting vasodilators which have the secondary action of enhancing cerebral metabolism (for example, dihydroergotoxine) are advocated as an adjunct in the treatment of "senile dementia." There is still disagreement about their practical benefit to patients, ${ }^{15-18}$ but small im- 
provements in behaviour and arousal have been reported. ${ }^{18}$ Exton-Smith et al suggested that higher doses of such agents may produce improvements in cognition. ${ }^{19}$ Perhaps the emphasis of the debate should be changed to consideration of which patients are likely to benefit from enhancement of their cerebral metabolism. Is it those with least derangement of metabolism and little structural damage or those with most derangement of metabolism and most structural damage? If the proposed division of Alzheimer's disease is confirmed then clinical trials in carefully characterised homogeneous groups of patients may produce more meaningful results.

Many of the drugs in the miscellaneous group have been reviewed by Reisberg. ${ }^{20}$ Clinical trials have been few, and the physiopathological basis for their use is in most cases tenuous. Opioid overactivity is said to occur in Alzheimer's disease due to a reduction in the inhibitory influence of $\gamma$-aminobutyric acid on opiate systems: and so opiate antagonists (naloxone) have been proposed as a treatment of Alzheimer's disease. Clinical trials of naloxone have been inconclusive. Vasopressin has also been postulated to have an enhancing effect on memory in normal people, ${ }^{21}$ but no improvement in memory function has been shown in people with brain damage. ${ }^{22}$

A new class of cerebrally active substances, the "nootropics," has been used in dementia with inconclusive results. An example is piracetam, a cyclic derivative of $\gamma$-aminobutyric acid, which is said to increase synthesis of adenosine-5'-triphosphate and enhance release of acetylcholine in the hippocampus. Further investigations are being undertaken to study its use in combination with precursors of choline synthesis.

The cholinergic treatment strategy has been reviewed by Johns et al and Rosenburg et al. ${ }^{23}$ This strategy has the merit of being derived from established biochemical abnormalities in Alzheimer's disease. Three approaches have been tried in attempts to enhance cholinergic activity: use of precursors (choline or lecithin); use of anticholinesterases (physostigmine); or use of muscarinic receptor agonists (arecholine). Clinical trials of precursors have been almost uniformly negative,,$^{23}$ and giving such substances causes practical problems as they are bulky -and it is also debatable whether such agents increase the amount of central cholinergic activity. ${ }^{23}$ Anticholinesterases have produced clinical improvement in some patients, but the short half life of physostigmine limits its usefulness. Both these strategies are open to the criticism that they are attempting to induce change in the defective presynaptic part of the cholinergic system. The third strategy, use of muscarinic agonists, avoids this criticism as the muscarinic receptors are intact. Many such agents, however, have short half lives. Longer acting agents such as oxotremarine await evaluation.

It is still too early to evaluate the place of the cholinergic strategy in the treatment of Alzheimer's disease. Levy has argued that to expect clinical improvement may be asking too much of such drugs, and that drug trials should be designed to assess whether the test substance can slow down the disease process rather than producing measurable improvement. ${ }^{25}$

Does discovery of cholinergic abnormalities in Alzheimer's disease bring promise of a therapeutic breakthrough akin to those which have occurred in Parkinson's disease as the result of identifying a dopamine deficiency? Such a parallel assumes that the deficit in the cholinergic system is the fundamental lesion in Alzheimer's disease, and this assumption is not yet entirely upheld by current pathophysiological findings; nor have attempts to make good that deficiency had unequivocal success. The current generation of "antidementia drugs" is heterogeneous, containing both drugs of great theoretical interest and of rational derivation and others that seem inherently less likely to be relevant or useful. For the present even those few that have shown some consistent improvements seem to offer neither sufficiently practical nor sufficiently sustained benefits to justify their general use-outside a research setting.

JANE BYRNE Lecturer

TOM ARIE Professor

Department of Health Care of the Elderly,

Queen's Medical Centre,

Nottingham NG7 2UH

1 Bondareff W. Age and Alzheimer's disease. Lancet 1983;i:1447.

Mountioy CQ, Rossor MN, Iversen LL, Roth M. Correlation of cortical cholinergic and GABA deficits with quantitative neuropathological findings in senile dementia. Brain 1984;107:507-18.

Davies P, Katzman R, Terry RD. Reduced somatostatin-like immunoreactivity in cerebral cortex from cases of Alzheimer disease and Alzheimer senile dementia. Nature 1980;288:279-80.

4 Perry EK, Tomlinson BE, Blessed G, Perry RH, Cross AJ, Crow TJ. Neuropathological and biochemical observations on the noradrenergic system in Alzheimer's disease. I Neurol Sci
1981;51:279-87.

Mann DMA, Lincoln J, Yates PO. Changes in the monoamine containing neurones of the human CNS in senile dementia. Br $\mathcal{Y}$ Psychiatry 1980;136:533-54

6 Benton JS, Bowen DM, Allen SJ, et al. Alzheimer's disease as a disorder of the isodentritic core. Lancet 1982;i:456.

7 Perry EK, Marshall EF, Blessed G, et al. Decreased imipramine binding in the brains of patients with depression. Br $\mathcal{F}$ Psychiatry 1983;142:188-92.

8 Yates CM, Allison Y, Simpson J, Maloney AF, Gordon A. Dopamine in Alzheimer's disease and senile dementia. Lancet 1979;ii:851-2.

9 Ball MJ, Hachinski V, Fox A, et al. A new definition of Alzheimer's disease: a hippocampal dementia. Lancet 1985; i: 14-6.

10 Hyman BT, van Hoesen GW, Damasio AR, Barnes CL. Alzheimer's disease: cell-specific pathology isolates the hippocampal formation. Science 1984;225:1168-70.

11 Grady CL. Neuropsychology and cerebral metabolism in normal aging. In: Cutler NR, moderator. Brain imaging and dementia. Ann Intern Med 1984;101:358-60.

12 Cutler NR. Brain metabolism in Alzheimer's disease. In: Cutler NR, moderator. Brain imaging and dementia. Ann Intern Med 1984;101:360-2.

13 Chase TN, Foster NL, Fedio P, Brooks R, Mansi L, Di Chiro G. Regional cortical dysfunction in Alzheimer's disease as determined by positron emission tomography. Ann Neurol 1984; 15(suppl): $170-4$.

14 Fieschi C, Lenzi GH. The aging brain and its metabolic balance: positron emission tomography results and prospects. In: Samuel D, Algeri S, Gershon S, Grimm VE, Tuffano G, eds. Aging of the brain. Vol 22. New York: Raven Press, 1983:123-31.

15 Anonymous. Vasodilators in senile dementia [Editorial]. Br Med $\mathcal{J}$ 1979;ii:511-2.

16 Branconnier RJ. The efficacy of cerebral metabolic enhancers in the treatment of senile dementia. Psychopharmacol Bull 1983;19(2):212-9.

17 Yesavage JA, Tinklenberg JR, Hollister LE, Berger PA. Vasodilators in senile dementia: a review of the literature. Arch Gen Psychiatry 1979;36:220-3.

18 McDonald RJ. Hydergine: a review of 26 clinical studies. Pharmakopsychiatrie 1979;12:407-22.

19 Exton-Smith AN, Piper M, Phillips M, Simpson J. Clinical experiences with ergot alkaloids. In: Agnoli A, Crepaldi G, Spano PF, Trabucchi M, eds. Aging brain and ergot alkaloids. New York: Raven Press, 1983:323-8.

20 Reisberg B, London E, Ferris SH, Anand R, deLeon MJ. Novel pharmacological approaches in the treatment of senile dementia of the Alzheimer type. Psychopharmacol Bull 1983;19(2):220-5.

21 Weingartner $\mathrm{H}$, Gold $\mathrm{P}$, Ballenger JC, et al. Effects of vasopressin on human memory functions. Science 1981;211:601-3.

22 Fewtrell WD, House AO, Jamie PF, Oates MR, Cooper JE. Effects of vasopressin on memory and new learning in a brain injured population. Psychol Med 1982;12:423-5.

23 Johns CA, Greenwald BS, Mohs RC, Davis KL. The cholinergic treatment strategy in aging and dementia. Psychopharmacol Bull 1983;19(2):185-97.

24 Rosenburg GS, Greenwald B, Davis KL. Pharmacologic treatment of Alzheimer's disease: an overview. In: Reisberg B, ed. Alzheimer's disease the standard reference. New York: Free Press, 1983:329-39.

25 Levy R. Choline in Alzheimer's disease. Lancet 1978;ii:944-5.

\section{What do you work with?}

The days are gone when patients working in industry handled only a few harmful substances such as lead, brass, and silica. Rapid advances in technology have resulted in workers being exposed to a much wider range of harmful or possibly harmful substances. No doctor can have a full knowledge of all forms of industrial exposure, so what action should he take when he or she (or increasingly nowadays the patient) raises the question "could the illness be due to something at work?” 